\title{
The Mediating Roles of Gender and Academic Field in the Relationship between Vocabulary Knowledge and Reading Comprehension of EFL Students
}

\author{
Hamad H. Alsowat \\ College of Education, Taif University, Saudi Arabia
}

Received November 22, 2021; Revised December 26, 2021; Accepted January 25, 2022

\section{Cite This Paper in the following Citation Styles}

(a): [1] Hamad H. Alsowat, "The Mediating Roles of Gender and Academic Field in the Relationship between Vocabulary Knowledge and Reading Comprehension of EFL Students," Universal Journal of Educational Research, Vol. 10, No. 2, pp. 146-159, 2022. DOI: 10.13189/ujer.2022.100204.

(b): Hamad H. Alsowat (2022). The Mediating Roles of Gender and Academic Field in the Relationship between Vocabulary Knowledge and Reading Comprehension of EFL Students. Universal Journal of Educational Research, 10(2), 146-159. DOI: 10.13189/ujer.2022.100204.

Copyright $\bigcirc 2022$ by authors, all rights reserved. Authors agree that this article remains permanently open access under the terms of the Creative Commons Attribution License 4.0 International License

\begin{abstract}
This study examined the mediating roles of gender and academic field in the relationship between vocabulary knowledge and reading comprehension. A vocabulary size test, a vocabulary depth test and the IELTS reading test were administered to 319 university-level students (54 males; 265 females) from three disciplines: medicine, science, and arts. The findings revealed that students had between 2000 and 3000 word families, low vocabulary depth $(45.3 \%)$, and poor reading comprehension (52.4\%). Besides, male students outperformed female students in all study variables. Meanwhile, medical students had superiority over science and arts students in Vocabulary Level Test (VLT) and reading comprehension. Vocabulary breadth and depth were significantly correlated with reading comprehension. The contribution of VLT and Depth of Vocabulary Knowledge (DVK) to reading comprehension differs depending on gender and academic field.
\end{abstract}

Keywords Academic Field, EFL Students, Gender, Reading Comprehension, Vocabulary Knowledge

\section{Introduction}

Vocabulary plays a vital role in learning a foreign or a second language. Vocabulary knowledge comprised at least two dimensions: vocabulary breadth and vocabulary depth. Vocabulary breadth points to the number of words that a learner knows, whereas vocabulary depth is related to the quality of a learner's vocabulary knowledge and how well a learner uses and masters the meaning of a word or a set of words [1], [17], [61]. In addition, vocabulary knowledge is a prerequisite for successful reading comprehension. Vocabulary knowledge helps learners comprehend written texts, and reading contributes to vocabulary growth [14], [53]. Students with inadequate vocabulary face difficulties comprehending the written texts, which negatively affects their academic performance. Adequate vocabulary knowledge is essential to reading comprehension. University students are expected to read and comprehend English texts easily [43]. However, many of them face severe difficulties reading and comprehending written texts due to the little interest in reading in English [49], problems in comprehending the texts and insufficient vocabulary size [67], ambiguous words, and unfamiliar vocabulary [33], [48].

Vocabulary knowledge and reading comprehension are directly related to each other. Research has shown a positive relationship between vocabulary knowledge and L2 reading comprehension. A substantial number of studies have shown strong positive correlations between vocabulary breadth and reading comprehension ranging from .50 to .87 among L2 learners of different educational and proficiency levels (e.g., [14], [10], [44], [46], [50], [60], 
[61], [62], [64]). In addition, many studies have focused on exploring the relationship between vocabulary depth and reading comprehension and have shown strong positive correlations ranging from .74 to .87 among L2 learners (e.g., [1], [10], [46], [50], [60], [61], [62], [64]). From a different perspective, several researchers conducted studies on the relationships between the main two constructs of vocabulary knowledge: breadth and depth, and they reported strong positive correlations ranging from .70 to .87 (e.g., [10], 17, [46], [60], [62], [64]). In a recent meta-analysis study, Zhang and Zhang [82] analyzed more than 100 individual studies to investigate the relationship between vocabulary knowledge and L2 reading comprehension. They found that the overall correlation between vocabulary knowledge and L2 reading comprehension was .57.

Academic field and gender are among the factors that contribute to the differences in vocabulary knowledge and reading comprehension. However, few studies focus on the influences of these variables on vocabulary knowledge and reading comprehension. The research results pointed out that gender affects vocabulary knowledge (e.g., [7], [9], [26], [27]). These differences affect reading comprehension since vocabulary usage is different across different academic fields [54]. In addition, research has revealed that gender influences students' reading comprehension (e.g., [3], [11], [15], [20], [68], [78]). Regarding academic fields, research has revealed that students' academic fields can affect their vocabulary knowledge (e.g., [22], [34]).

Although the studies mentioned above focused on the overall relationship between the aspects of vocabulary knowledge and reading comprehension and the effects of gender and academic field on these variables, the research did not examine students' gender and academic field (medicine, science, or arts) as mediators that may have potential influences on the relationship between vocabulary knowledge and reading comprehension. Therefore, a better understanding of the effect of gender and academic field as mediating variables is warranted. So, this study comes to bridge this research gap by developing an evidence-based framework for vocabulary knowledge and reading comprehension with respect to gender and academic field. Therefore, the present study attempts to empirically investigate the contribution of gender and academic field (medicine, science, and arts) to the relationship between vocabulary breadth, vocabulary depth, and reading comprehension of EFL learners. This study is expected to have significant implications for vocabulary learning and reading comprehension in a manner that would enable students to improve their vocabulary knowledge aspects to support their reading comprehension. In addition, the results of this research are also expected to guide the focus of teaching and learning processes when teaching vocabulary to students of different gender and disciplines.

\section{Literature Review}

\subsection{The Relationship between Vocabulary Knowledge and Reading Comprehension}

Reading is a receptive skill that is essential for understanding written texts. Reading comprehension is a complicated process that encompasses the coordination of a range of knowledge, abilities, and strategies that require cognitive and linguistic processes [18], [25]. Reading comprehension involves abilities of processing skills and syntactic knowledge, reading strategies to support deep comprehension, high-level processing to the strategic reader, discourse knowledge and cognitive skills, interpreting and evaluating texts, and processing texts fluently [28]. Vocabulary knowledge is among the variables involved in reading comprehension [44]. The strong relationship between vocabulary knowledge and reading comprehension of written texts emphasizes the significant role that vocabulary knowledge plays in reading comprehension [43].

The breadth of vocabulary knowledge refers to the number of words and reflects the quantity of words that a learner knows at a particular level of proficiency [53], [62], or "the size of a language learner's L2 mental lexicon" [63, p. 35]. Nation and Waring [54] stated that although there are more than 54,000 word families in English, and although educated native speakers know about 20,000 words family, 3,000 to 5,000 words families would be sufficient for reading comprehension. They added that 2,000 to 3,000 word families would be necessary for language production in speaking and writing. Adult EFL learners who studied English for several years know less than 5,000 words families [52]. Many studies have investigated the relationship between vocabulary breadth and L2 reading comprehension. An early attempt was carried by Laufer [37], who reported a high positive correlation between vocabulary size and reading comprehension of college L2 learners $(r=.50, p . \leq 0.001)$. Qian [61], [62] investigated the relationship between vocabulary breadth and reading comprehension and reported a strong positive relationship between breadth and L2 reading comprehension ranging from .74 to .78. Stæhr [73] also investigated the relationship between vocabulary size and reading comprehension among 88 Danish EFL learners. Results indicated that learners' vocabulary size was strongly associated with their reading comprehension $(\mathrm{r}=.83, \mathrm{p} . \leq 0.01)$, indicating that vocabulary size has predicted $72 \%$ of the variance in reading comprehension. Anjomshoa and Zamanian [14] investigated the effect of vocabulary size on reading comprehension of 81 Iranian EFL undergraduate students. The findings revealed a significant positive relationship between vocabulary size and reading comprehension $(\mathrm{r}=.60, \mathrm{p} . \leq .001)$. In Saudi Arabia, Masrai [44] examined the degree to which high-, mid- and low-frequency vocabulary could predict reading comprehension of 256 university students majoring in the English language. The finding revealed that vocabulary 
size across high- and mid-frequency ranges was strongly correlated with $\mathrm{L} 2$ reading comprehension $(\mathrm{r}=.63$ to .77 , p. $\leq .001$ ). [4] determined the role of vocabulary size in reading L2 reading comprehension among 64 Saudi male EFL learners at King Khalid University. The results revealed that the learners' vocabulary size was 2025 word families, and there was a significant positive relationship between vocabulary size and reading comprehension $(\mathrm{r}=.48, \mathrm{p} . \leq .001)$.

The depth of vocabulary knowledge refers to the quality of lexical knowledge [66] and how well a learner knows a lexical item to use it well in language production [69]. Vocabulary depth is as crucial as vocabulary size since it constitutes a framework for evaluating a learner's lexical development ([57]). Qian [62] stated that vocabulary depth consists of "all word characteristics such as phonemic, graphemic, morphemic, syntactic, semantic, collocational and phraseological properties" (p. 516). Abedi [1] explored the relationship between the vocabulary depth of 50 Iranian EFL learners and their reading comprehension. The findings showed a strong positive relationship between vocabulary depth and reading comprehension $(\mathrm{r}=.74$, $\mathrm{p} . \leq 0.01$ ). A substantial number of studies have investigated the relationship of both breadth and depth of vocabulary knowledge to L2 reading comprehension and have found that vocabulary breadth and vocabulary depth were positively correlated with reading comprehension. Some of these studies have revealed that vocabulary breadth is more correlated with reading comprehension (e.g., [10], [17], [23], [43], [50]), and others have shown that vocabulary depth is more correlated with reading comprehension (e.g., [46], [61], [62], [64], [72], [79]).

Interestingly, the research was not limited to examining the relationship between the breadth and depth of vocabulary knowledge and reading comprehension but went beyond to find the specific relationship between the breadth and depth of vocabulary knowledge. Those studies showed a strong positive relationship between these two vocabulary constructs, which indicates that the breadth of vocabulary is affected by the depth of vocabulary and vice versa. For example, Qian [61] reported a strong correlation between vocabulary breadth and depth among 74 Chinese and Korean learners $(\mathrm{r}=.82, \mathrm{p} . \leq .0 .1)$. Later, he conducted a study on 217 students from 19 L1 backgrounds. The findings revealed a slightly lower correlation $(\mathrm{r}=70, \mathrm{p} . \leq$ 0.01 ), which was probably due to the heterogeneous sample of this study compared to Qian's [61], which included a homogeneous sample [62]. In addition, two studies [10], [79] reported relatively high positive correlations between vocabulary breadth and depth $(\mathrm{r}=.89$, $\mathrm{p} . \leq .001)$. These findings might be due to the relatively low sample sizes, 64 and 30 respectively, or to the homogeneity of the study sample. The findings of several studies have shown somewhat similar positive correlations ranging from .73 to .84 [17], [23], [46], [64]. The lowest correlation reported among the reviewed studies was .56, which indicated a moderate positive relationship between the breadth and depth of vocabulary knowledge [43].

To conclude, the literature review proves consistent findings on the relationships between vocabulary knowledge and L2 reading comprehension. Therefore, vocabulary breadth and depth are considered strong predictors of reading comprehension. However, most previous studies have looked at the linear relationships between the overall vocabulary knowledge and reading ability ([44]), ignoring other variables such as gender and academic field that may mediate this relationship.

\subsection{Gender Differences in Vocabulary Knowledge and Reading Comprehension}

Gender is a crucial factor that has attracted researchers' attention in the field of L2 language learning. Gender is defined through sex (i.e., male or female). However, it "is not restricted to sex differences as gender is expressed through behavioral, interactional and personality characteristics" [21 p. 71]. Thus, gender belongs to individual factors that affect success in language learning. Unfortunately, the role of gender in language learning has been neglected for a long time [47].

Several studies have considered gender differences in vocabulary knowledge (i.e., breadth and depth). Studies indicated three pathways concerning the effect of gender on vocabulary knowledge. Firstly, some studies (e.g., [7], [9], [27]) showed that male students significantly outperformed female students in the aspects of vocabulary knowledge. For example, Alonso [7] investigated the vocabulary breadth of 92 Spanish secondary-school students learning English as a foreign language and reported a statistically significant difference in favor of male students. In addition, Fardad et al. [27] investigated the effect of gender on the vocabulary breadth of 88 Iranian male and female students from Khorasgan Azad University. They found that the mean score of male learners was significantly higher than female learners. More recently, [9] compared the vocabulary breadth of 71 Saudi male and female university-level students. Significant differences were reported in favor of male students in all the five levels of the Vocabulary Level Test (VLT). Secondly, some studies have confirmed significant differences in vocabulary knowledge in favor of female students. For example, Gu's study [30] showed that Chinese female EFL learners significantly outperformed male students in vocabulary size. More recently, Fan [26] explored how Chinese EFL learners' gender might affect their vocabulary breadth and found that female students significantly outperformed their male counterparts. Thirdly, several studies (e.g., [19], [39], [77]) indicated no significant gender differences in vocabulary knowledge. For instance, Catalan [19] conducted a study on Spanish EFL 12-year-old male and female learners, and the findings indicated no significant difference due to gender on the 1000-word and 2000-word families. In a Korean learning context, Lee [39] examined the effects of gender on EFL breadth and depth of vocabulary knowledge among 
492 learners. The finding indicated no significant gender-based differences in vocabulary knowledge. In addition, Yang [77] recruited 37 junior students to examine the impact of gender on their vocabulary breadth. The results showed that students' vocabulary breadth did not differ significantly due to gender.

Regarding gender differences in reading comprehension, the number of studies investigating the impact of gender on reading comprehension is limited. Most of the studies reviewed have shown no gender differences. For instance, Phakiti [59] conducted a study on 384 Thai university students and found that male and female students did not differ in reading comprehension. In addition, Mehrpour et al. [46] investigated the effect of gender among sixty Iranian EFL learners. They reported that gender had no significant impact on students' reading comprehension scores. Recently, Koc [35] examined gender differences of 60 university-level students and found that gender did not affect students' reading comprehension. For younger learners, McGeown et al. [45] investigated gender differences in reading comprehension of 182 learners. The finding indicated that gender did not have an impact on reading comprehension. Besides, the findings of Asgarabadi et al. [16] indicated that gender did not affect students' reading comprehension. Other studies have reported that females have significantly performed better than males in L2 reading comprehension. For example, for young learners, Salehi et al. [68] reported gender differences in reading comprehension of different genres in favor of females. In addition, Cekiso [20] explored the gender differences in reading comprehension among 95 third-grade and reported a significant difference in the reading comprehension test in favor of girls. Besides, Anjum [15] explored gender differences at the primary stage, and the findings indicated that girls were significantly higher than boys in reading comprehension. At the college level, Payne \& Lynn [58] came to the same findings suggesting that females had a more robust segment for L2 processing than males. Nevertheless, few studies reported that male students significantly outperformed female students in reading comprehension at the university level [3], [11], [78].

In summary, the reviewed studies focused on the isolated impact of gender and indicated mixed results regarding the role of gender differences in vocabulary knowledge and reading comprehension. Thus, they ignored the mediated role of gender in the relationship between vocabulary knowledge and reading comprehension. Therefore, further research is warranted to explain gender differences [4], [24] to know accurately the variance in the relationship between reading comprehension and vocabulary knowledge (i.e., breadth and depth) that is explained by gender.

\subsection{Effects of Academic Field on Vocabulary Knowledge and Reading Comprehension}

Academic field is the second mediated variable examined in this study. In EFL contexts, it is generally recognized that arts students may have an advantage over science students in English language acquisition [81] since arts students employ more learning strategies than their science counterparts. However, there has been scant research to examine the impact of academic field on vocabulary learning. $\mathrm{Gu}$ [30] investigated the correlation between academic field and language learning outcomes. Results indicated that academic field was a less determining background factor in language learning. Although science students insignificantly outperformed arts students in vocabulary size, arts students were significantly higher than science students on the general proficiency test. Kruekaew et al. [36] investigated factors affecting Thai undergraduates' English vocabulary skills. The sample included 785 undergraduates from 6 faculties (7 academic fields) at Prince of Songkla University. The findings revealed that academic field was correlated with vocabulary skills; students majoring in Languages did significantly better than other students. In a recent study, Fan [26] examined how academic field might contribute to Chinese EFL learners' vocabulary knowledge (i.e., breadth and depth). The findings showed that science and engineering students performed significantly better than humanities and social sciences students.

With regards to reading comprehension, reading is a crucial constituent in every academic discipline. Reading comprehension could be either hindered or facilitated by students' discipline knowledge [22]. However, there has been limited research regarding the effect of academic field on reading comprehension. For example, Chigayeva [22] conducted a study on 252 non-native speakers of English and reported that academic-field knowledge had an impact on reading comprehension. Khodadady and Dastgahian ([34]) explored the relationship between academic field and reading comprehension of 5183 university students using an English Language Proficiency Test. They found that medical science and engineering scores were significantly higher than those of humanities and social sciences. Recently, Kasim et al. [32] explored the differences between 179 social and natural sciences students in reading compression due to academic discipline. They concluded that academic discipline did not affect reading comprehension except for the aspect of the main idea.

In sum, the studies above highlighted the effect of academic field on vocabulary knowledge and reading comprehension independently. However, research investigating the mediating role of academic field and its contribution to the relationship between vocabulary knowledge and reading comprehension is still undetermined.

\subsection{The Present Study}

The study aimed to investigate the relationship between vocabulary knowledge (i.e., breadth and depth) and reading comprehension of Saudi undergraduate students. 
Moreover, it aimed at investigating the effect of gender and academic field as mediating variables on the relationship between vocabulary knowledge and reading comprehension. Although vocabulary knowledge has been widely investigated in relation to reading comprehension, the contribution of gender and academic field to the relationship between vocabulary knowledge and reading comprehension is still undecided. Therefore, students' scores on vocabulary breadth (The Updated VLT) and Depth of Vocabulary Knowledge (WAT), and reading comprehension were assessed. In addition, gender and academic field were inserted as mediating factors to measure their effect on the relationship between vocabulary knowledge and reading comprehension. To this end, the present study addressed the following questions:

RQ1: What is Saudi undergraduates' performance on vocabulary breadth, depth, and reading comprehension?

RQ2: Are there any statistically significant differences between the participants' scores on vocabulary breadth, vocabulary depth, and reading comprehension due to gender and academic field?

RQ3: What is the nature of the correlations between vocabulary breadth, vocabulary depth, and reading comprehension?

RQ4: How are the interrelationships between vocabulary breadth, vocabulary depth, and reading comprehension mediated by gender?

RQ5: How are the interrelationships between vocabulary breadth, vocabulary depth, and reading comprehension mediated by academic field?

\section{Method}

\subsection{Participants}

A total of 319 EFL university-level students from Taif University in Saudi Arabia participated in the study. The students were from the first to the fourth year, and their language proficiency varied from beginners to advanced. Their ages ranged between 18 and 24 years, and they have studied the English language for at least ten years. They were distributed by gender (54 males; 265 females) and academic field (44 medicine; 115 science; 160 arts). The participants' first language is Arabic. All participants completed the updated Vocabulary Level Test (VLT), Depth of Vocabulary Knowledge (DVK), and IELTS reading test. In addition, they provided their demographic characteristics and completed a consent form.

\subsection{Instruments}

\subsubsection{Background Questionnaire}

A questionnaire was provided to obtain demographic characteristics on participants' academic field, length of learning English, age, and education level.

\subsubsection{Vocabulary Level Test (VLT)}

The updated Vocabulary Level Test [76] was adopted to measure vocabulary size. The updated VLT was chosen due to the time constraint and because most Saudi college students' average vocabulary size is below 3000-word families [9], [12]. The updated VLT consisted of five levels measuring the receptive vocabulary knowledge at 1000 , $2000,3000,4000$, and 5000 levels. The updated VLT was presented in a grid with the definitions presented vertically down the page and the items presented horizontally across the page. Each level consisted of 10 clusters of three definitions and six words (three keys and three distractors). An example from the 2000 word level was presented in table 1 .

Table 1. A cluster from the 2000 word level

\begin{tabular}{|c|c|c|c|c|c|c|}
\hline & apartment & cap & envelope & lawyer & speed & union \\
\hline cover & & \multirow{9}{*}{$\sqrt{ }$} & \multirow{9}{*}{$\sqrt{ }$} & & & \\
\hline for & & & & & & \\
\hline letters & & & & & & \\
\hline kind of & & & & & & \\
\hline place to & \multirow{5}{*}{$\sqrt{ }$} & & & & & \\
\hline live & & & & & & \\
\hline inside a & & & & & & \\
\hline tall & & & & & & \\
\hline building & & & & & & \\
\hline
\end{tabular}

There were 30 definitions at each level. For each correct answer in a cluster, the test taker received a point, so the maximum score at each level was 30 points. The maximum possible score for the whole VLT was 150 points. The test taker had to tick the correct item box for each definition. Students were given 50 minutes to finish the VLT test. The reliability of the whole updated VLT was .97 , which was almost similar to the reliability found by Webb et al. [76].

\subsubsection{Depth of Vocabulary Knowledge (DVK)}

Depth of Vocabulary Knowledge (DVK) is intended to measure learners' depth of receptive English vocabulary knowledge. DVK measures two aspects of vocabulary depth: meaning (synonymy and polysemy) and collocation [60]. This test was originally developed by Read [65] and was called the Word Associates Test (WAT). A modified version of the DVK, used in this study, contains 40 items; 32 items were original WAT, and eight items were developed by Qian [60] to replace eight original items which were considered ambiguous. Each item consists of one stimulus adjective and two boxes, each containing four words. One to three words in the left box can be synonymous to the whole meaning or one aspect of the stimulus word, whereas one to three words in the right box can be collocations of the stimulus word. Thus, there are four correct answers for each item. However, the four answers are not equally spread. There are three possible situations: (a) each box contains two correct answers, (b) the left box contains one correct answer, and the right box contains three correct answers; and (c) the left box contains three correct answers, and the right box contains only one correct answer [62]. Table 2 shows an example of the DVK test of the stimulus word, common. 
Table 2. An example of the DVK items common

\begin{tabular}{|c|c|c|c|}
\hline complete & light & ordinary & shared \\
\hline & & $\checkmark$ & $\checkmark$ \\
\hline
\end{tabular}

\begin{tabular}{|c|c|c|c|}
\hline boundary & circle & name & party \\
\hline$\checkmark$ & & $\checkmark$ & \\
\hline
\end{tabular}

The correct answers for the stimulus word, common, are ordinary and shared in the left box and boundary and name in the right box. In scoring DVK, each word correctly chosen was given one point. Thus, the maximum possible score for the 40 items was 160 . The participants were given 30 minutes to complete the DVK test as recommended by Qian [60], who stated that DVK was an efficient instrument that intermediate learners could complete within 30 minutes. Reliability obtained for the DVK test has reached .91 [60], .88 [62], and .91 [46]. The reliability index obtained in this study was .92 .

\subsubsection{Reading Comprehension Test}

A version of the IELTS general reading subset was selected to measure the participants' reading comprehension (RC). IELTS is a standardized assessment of English language proficiency that is used worldwide for academic purposes. The reading subset used in this study consisted of three sections. The first section (questions 1-13), the second section (questions 14-28), and the third section (questions 29-40) had varied types of questions, including identifying information, multiple choices, sentences completion, true false, identifying the main ideas and matching information. For scoring the IELTS reading comprehension test, each correct answer was worth one point. Thus, the maximum possible score was 40 points. The instructions were clearly provided for the participants, and they were given 60 minutes to complete the test. The reliability of the test has reached .86 .

\subsection{Data Collection Procedure}

The three instruments, VLT, DVK, and the reading comprehension test, were administered to the participants in three successive sessions in students' English lectures. The test proctors were provided with the instructions for administering the instruments. The participants were instructed on the aim of the instruments and informed that their results on the tests would not affect their course assessment. In the first session, the VLT test was administered to the participants for 50 minutes. Then, the DVK test was administered in the second session for 30 minutes. Finally, the reading comprehension test was administered in 60 minutes.

\subsection{Data Analysis}

The data obtained were coded and analyzed using SPSS (version 23). The descriptive statistics of the participants' demographic characteristics and scores on the three tests (i.e., VLT, DVK, and reading comprehension) were calculated. To examine the differences between the participants' scores on the three tests due to gander and academic field, independent samples t-test and one-way ANOVA were conducted, respectively. Pearson correlation coefficient was used to determine the correlations between the variables of the study. Hierarchical multiple regression was run to examine the contribution of vocabulary knowledge (breadth and depth), gender, and academic field to reading comprehension. Vocabulary knowledge (breadth and depth), gender, and academic field were the independent variables, while reading comprehension was the dependent variable.

\section{Results}

Research Question 1: What is Saudi undergraduates' performance on vocabulary breadth, depth, and reading comprehension?

The descriptive statistics of the participants' scores on vocabulary breadth showed that the mean score of the 1000 -word level gained the highest score (73.3\%). On the other hand, the scores vastly decreased, reaching only $47.4 \%$ for the 5000 -word level, indicating insufficient vocabulary knowledge. Table 3 also shows the percentages of 2000,3000 , and 4000 -word levels. They were $52.2 \%$, $49.1 \%$, and $48.3 \%$ respectively. Thus, the overall vocabulary knowledge of the participants was approximately 2700 word families.

Table 3. Descriptive statistics of the Vocabulary Level Test (VLT) ( $n=$ 184)

\begin{tabular}{|c|c|c|c|c|c|}
\hline Levels & MPS & $\begin{array}{c}\text { Mean } \\
(\%)\end{array}$ & SD & Words & Reliability \\
\hline $\begin{array}{c}\text { Level } \\
1000\end{array}$ & 30 & $\begin{array}{l}21.99 \\
(73.3)\end{array}$ & 9.90 & 733 & .93 \\
\hline $\begin{array}{c}\text { Level } \\
2000\end{array}$ & 30 & $\begin{array}{l}15.66 \\
(52.2)\end{array}$ & 9.67 & 522 & .88 \\
\hline $\begin{array}{c}\text { Level } \\
3000\end{array}$ & 30 & $\begin{array}{l}14.73 \\
(49.1)\end{array}$ & 10.04 & 491 & .90 \\
\hline $\begin{array}{c}\text { Level } \\
4000\end{array}$ & 30 & $\begin{array}{l}14.49 \\
(48.3)\end{array}$ & 9.98 & 483 & .89 \\
\hline $\begin{array}{c}\text { Level } \\
5000\end{array}$ & 30 & $\begin{array}{l}14.22 \\
(47.4)\end{array}$ & 9.89 & 474 & .88 \\
\hline
\end{tabular}

Note. $\mathrm{MPS}=$ Maximum possible score

Table 4 displays the mean scores and standard deviations of the participants' performance on the vocabulary knowledge subcomponents and the reading comprehension test. 
Table 4. Summary of the descriptive statistics $(n=184)$

\begin{tabular}{|c|c|c|c|c|}
\hline Variable & MPS & $\begin{array}{c}\text { Mean } \\
(\%)\end{array}$ & SD & Reliability \\
\hline VLT & 150 & $\begin{array}{l}81.04 \\
(54.3)\end{array}$ & 15.18 & .97 \\
\hline DVK & 160 & $\begin{array}{l}72.43 \\
(45.3)\end{array}$ & 18.86 & .92 \\
\hline DVKM & 76 & $\begin{array}{l}39.94 \\
(52.6)\end{array}$ & 8.10 & .88 \\
\hline DVKC & 84 & $\begin{array}{l}32.48 \\
(38.7)\end{array}$ & 9.90 & .90 \\
\hline $\mathrm{RC}$ & 30 & $\begin{array}{l}15.71 \\
(52.4) \\
\end{array}$ & 5.49 & .86 \\
\hline
\end{tabular}

Note. VLT $=$ Vocabulary Level Test, DVK=Depth of Vocabulary Knowledge, DVKM=Meaning, $\quad \mathrm{DVKC}=$ Collocation, $\mathrm{RC}=$ Reading comprehension, MPS=Maximum possible score

The participants' performance on VLT (54.3\%) was higher than on DVK (45.3\%). Comparatively, the mean score of word meaning $(52.6 \%)$ was noticeably higher than knowledge of collocation (38.7\%). On the other hand, the mean score of the reading comprehension test revealed that the participants achieved only $52.4 \%$ of text comprehension, which also indicated students' low reading proficiency.

Research Question 2: Are there any statistically significant differences between the participants' scores on vocabulary breadth, vocabulary depth, and reading comprehension due to gender and academic field?

Independent-samples t-test was run to explore the differences between male and female students in vocabulary knowledge aspects and reading comprehension, as shown in Table 5. The results indicated statistically significant differences between the mean scores of VLT $[\mathrm{t}=2.96, \mathrm{p}<.05$, Cohen's $\mathrm{d}=.58]$, DVK $[\mathrm{t}=3.42, \mathrm{p}<.05$, Cohen's $\mathrm{d}=.67]$, and the reading comprehension test $[\mathrm{t}=1.98, \mathrm{p}<.05$, Cohen's $\mathrm{d}=.38]$ in favor of male students.

One-way ANOVA was performed to examine the differences between the participants' scores on VLT, DVK, and the reading comprehension test due to academic field, as shown in Table 6.

The results revealed that academic field did not affect the participants' scores on DVK, while there were statistically significant differences in terms of VLT and the reading comprehension test. Medical students significantly outperformed arts students on the VLT test $[\mathrm{F}=4.238$, $\mathrm{p}<.05]$, while the differences between medicine and science students and science and arts students were not significant. Medical students were significantly higher than science and arts students $[\mathrm{F}=8.508, \mathrm{p}<.05]$ in the reading comprehension test. Although science students' scores were higher than the scores of arts students, the difference was not significant.

Table 5. Results of independent sample t-test for gender differences

\begin{tabular}{|c|c|c|c|c|c|c|c|c|c|}
\hline \multirow{2}{*}{ Variable } & \multirow{2}{*}{ Group } & \multirow[t]{2}{*}{$\mathbf{N}$} & \multicolumn{2}{|c|}{$\begin{array}{c}\text { Levene's Test for Equality } \\
\text { of Variances }\end{array}$} & \multirow[t]{2}{*}{ Mean } & \multirow[t]{2}{*}{$\mathbf{t}$} & \multirow[t]{2}{*}{ df } & \multirow[t]{2}{*}{ Sig. } & \multirow[t]{2}{*}{ Cohen's d } \\
\hline & & & F & Sig. & & & & & \\
\hline \multirow{2}{*}{ VLT } & Males & 54 & \multirow{2}{*}{.096} & \multirow{2}{*}{.76} & 102.50 & \multirow{2}{*}{2.96} & \multirow{2}{*}{317} & \multirow{2}{*}{.003} & \multirow{2}{*}{.58} \\
\hline & Females & 265 & & & 76.70 & & & & \\
\hline \multirow{2}{*}{ DVK } & Males & 54 & \multirow{2}{*}{.068} & \multirow{2}{*}{.80} & 91.42 & \multirow{2}{*}{3.42} & \multirow{2}{*}{317} & \multirow{2}{*}{.001} & \multirow{2}{*}{.67} \\
\hline & Females & 265 & & & 68.58 & & & & \\
\hline \multirow{2}{*}{$\mathrm{RC}$} & Males & 54 & \multirow{2}{*}{.775} & \multirow{2}{*}{.38} & 19.10 & \multirow{2}{*}{1.98} & \multirow{2}{*}{317} & \multirow{2}{*}{.049} & \multirow{2}{*}{.38} \\
\hline & Females & 265 & & & 15.03 & & & & \\
\hline
\end{tabular}

Table 6. Results of one-way ANOVA for academic field differences

\begin{tabular}{|c|c|c|c|c|c|c|c|c|c|}
\hline \multirow{3}{*}{ Variable } & \multicolumn{3}{|c|}{ Mean } & \multirow{2}{*}{\multicolumn{2}{|c|}{$\begin{array}{l}\text { Homogeneity of } \\
\text { Variances }\end{array}$}} & \multirow{3}{*}{$\mathbf{F}$} & \multirow{3}{*}{ Sig. } & \multirow{3}{*}{ Tukey HSD } & \multirow{3}{*}{ Sig. } \\
\hline & \multirow{2}{*}{$\begin{array}{c}\text { Medicine } \\
\mathrm{n}=44 \\
\end{array}$} & \multirow{2}{*}{$\begin{array}{r}\text { Science } \\
\mathrm{n}=115 \\
\end{array}$} & \multirow{2}{*}{$\begin{array}{c}\text { Arts } \\
\mathrm{n}=160\end{array}$} & & & & & & \\
\hline & & & & Levene & Sig. & & & & \\
\hline VLT & 102.05 & 82.15 & 74.47 & .87 & .42 & 4.238 & .016 & Medicine $>$ Arts & .012 \\
\hline DVK & 78.72 & 67.24 & 73.63 & .85 & .43 & 1.147 & .320 & - & - \\
\hline $\mathrm{RC}$ & 22.64 & 15.82 & 13.74 & .22 & .80 & 8.508 & .000 & $\begin{array}{c}\text { Medicine }>\text { Science } \\
\text { Medicine }>\text { Arts }\end{array}$ & $\begin{array}{l}.010 \\
.000\end{array}$ \\
\hline
\end{tabular}


Research Question 3: What is the nature of the correlations between vocabulary breadth, vocabulary depth, and reading comprehension?

Table 7. Pearson correlation coefficients among VLT, DVK, DVKM, DVKC, and $\mathrm{RC}(\mathrm{n}=184)$

\begin{tabular}{ccccc}
\hline Variable & DVK & DVKM & DVKC & RC \\
\hline VLT & $.54^{* *}$ & $.58^{* *}$ & $.45^{* *}$ & $.67^{* *}$ \\
DVK & & $.93^{* *}$ & $.95^{* *}$ & $.57^{* *}$ \\
DVKM & & & $.77^{* *}$ & $.55^{* *}$ \\
DVKC & & & & $.52^{* *}$ \\
\hline
\end{tabular}

Note. VLT=Vocabulary Level Test, DVK=Depth of Vocabulary Knowledge, DVKM=Meaning, DVKC=Collocation, $\mathrm{RC}=$ Reading comprehension, **. Correlation is significant at the 0.001 level (2-tailed).

Pearson correlation analyses were conducted to investigate the correlations of VLT, DVK aspects with reading comprehension, as shown in Table 7 . The correlation coefficients revealed that VLT, DVK, DVKM, and DVKC were significantly correlated with reading comprehension. Vocabulary breadth had the highest correlation $(\mathrm{r}=.67, \mathrm{p}<.001)$, followed by vocabulary depth $(\mathrm{r}=.57, \mathrm{p}<.001)$. Lower significant correlations were found in the association of reading comprehension with word meaning $(\mathrm{r}=.55, \mathrm{p}<.001)$ and word collocation $(\mathrm{r}=.52$, $\mathrm{p}<.001)$. VLT was significantly correlated with DVK $(\mathrm{r}=.54, \mathrm{p}<.001)$, word meaning $(\mathrm{r}=.58, \mathrm{p}<.001)$, and word collocation ( $\mathrm{r}=.45, \mathrm{p}<.001)$. In addition, DVK was strongly correlated with word meaning $(\mathrm{r}=.093, \mathrm{p}<.001)$ and word collocation $(\mathrm{r}=.95, \mathrm{p}<.001)$. Besides, there was a strong correlation between word meaning and word association $(\mathrm{r}=.77, \mathrm{p}<.001)$.

Research Question 4: How are the interrelationships between vocabulary breadth, vocabulary depth, and reading comprehension mediated by gender?

As displayed in Table 8, the hierarchical multiple regression was performed to determine the contribution of gender to the interrelationships of VLT and DVK to reading comprehension. Results of step 1 revealed that VLT accounted for a significant variance in reading comprehension in males (39\%) and females $(46 \%), \beta=.62$, $\mathrm{p}<.01$ and $\beta=.68, \mathrm{p}<.01$. In step 2, DVK explained an additional $6 \%$ in the variance of reading comprehension for males, which was not statistically significant $(\beta=.27$, $\mathrm{p}>.05)$; the result was statistically significant for females $(\beta=.29, \mathrm{p}<.01)$ and explained an additional $6 \%$ in the variance of reading comprehension.

To this end, the two models explained $45 \%$ of the variance in reading comprehension scores for males and $51 \%$ for females, suggesting that VLT and DVK play a more significant role for female students.

Research Question 5: How are the interrelationships between vocabulary breadth, vocabulary depth, and reading comprehension mediated by academic field?

The results of the hierarchical multiple regression in Table 9 show that VLT significantly contributed to the prediction of reading comprehension in each model. In step 1 , VLT explained $47 \%, 36 \%$, and $46 \%$ of the variance in reading comprehension scores for medicine $(\beta=.69, p<.01)$, science $(\beta=.60, \mathrm{p}<.01)$ and arts students $(\beta=.68, \mathrm{p}<.01)$, respectively. When DVK entered in step 2, DVK explained an additional $4 \%, 8 \%, 7 \%$ in the variance of reading comprehension scores among medicine, science, and arts students, respectively. The results were statistically significant for science $(\beta=.33, \mathrm{p}<.01)$ and arts students $(\beta=.31, \mathrm{p}<.01)$ but not significant for medical students $(\beta=.28, \mathrm{p}>.05)$.

Table 8. Results of regression analysis for the contributions of gender to the relationship between vocabulary knowledge and reading comprehension

\begin{tabular}{|c|c|c|c|c|c|c|}
\hline \multirow{2}{*}{ Variables } & \multicolumn{3}{|c|}{ Males $(n=54)$} & \multicolumn{3}{|c|}{ Females $(n=265)$} \\
\hline & $\mathbf{R}^{2}$ & $\mathbf{B}(\boldsymbol{\beta})$ & $\Delta \mathbf{R}^{2}$ & $\mathbf{R}^{2}$ & $\mathbf{B}(\boldsymbol{\beta})$ & $\Delta \mathbf{R}^{2}$ \\
\hline Step 1 & $.39^{\mathrm{a}}$ & & $.39^{* *}$ & $.46^{\mathrm{a}}$ & & $.46^{* *}$ \\
\hline Constant & & 3.61 & & & 2.94 & \\
\hline VLT & & $.15(.62)^{* *}$ & & & $.16(.68)^{* *}$ & \\
\hline Step 2 & $.45^{\mathrm{b}}$ & & .06 & $.51^{\mathrm{b}}$ & & $.06^{* *}$ \\
\hline Constant & & -1.29 & & & -.342 & \\
\hline VLT & & $.12(.50)^{* *}$ & & & $.12(.52)^{* *}$ & \\
\hline DVK & & $.09(.27)$ & & & $.09(.29)^{* *}$ & \\
\hline
\end{tabular}

a. Predictors: (Constant), VLT, b. Predictors: (Constant), VLT, DVK, Dependent variable: RC, ${ }^{* *} \mathrm{p}<.01,{ }^{*} \mathrm{p}<.05$. 
Table 9. Results of regression analysis for the contributions of academic field to the relationship between vocabulary knowledge and reading comprehension

\begin{tabular}{|c|c|c|c|c|c|c|c|c|c|}
\hline \multirow{2}{*}{ Variables } & \multicolumn{3}{|c|}{ Medicine $(n=44)$} & \multicolumn{3}{|c|}{ Science $(n=115)$} & \multicolumn{3}{|c|}{ Arts $(n=160)$} \\
\hline & $\mathbf{R}^{2}$ & B ( $(\boldsymbol{\beta})$ & $\Delta \mathbf{R}^{2}$ & $\mathbf{R}^{2}$ & B ( $(\boldsymbol{\beta})$ & $\Delta \mathbf{R}^{2}$ & $\mathbf{R}^{2}$ & B ( $(\boldsymbol{\beta})$ & $\Delta \mathbf{R}^{2}$ \\
\hline Step 1 & $.47^{\mathrm{a}}$ & & $.47 * *$ & $.36^{\mathrm{a}}$ & & $.36 * *$ & $.46^{\mathrm{a}}$ & & $.46^{* *}$ \\
\hline Constant & & 4.7 & & & 5.4 & & & 2.15 & \\
\hline VLT & & $.18(.69)^{* *}$ & & & $.13(.60)^{* *}$ & & & $.16(68)^{* *}$ & \\
\hline Step 2 & $.51^{\mathrm{b}}$ & & .04 & $.44^{\mathrm{b}}$ & & $.08^{* *}$ & $.53^{\mathrm{b}}$ & & $.07 * *$ \\
\hline Constant & & 3.6 & & & 2.4 & & & -2.12 & \\
\hline VLT & & $.13(.49)^{*}$ & & & $.09(.42)^{* *}$ & & & $.12(52)^{* *}$ & \\
\hline DVK & & $.08(.28)$ & & & $.09(.33)^{* *}$ & & & $.09(31)^{* *}$ & \\
\hline
\end{tabular}

a. Predictors: (Constant), VLT, b. Predictors: (Constant), VLT, DVK, Dependent variable: RC, ${ }^{* *} \mathrm{p}<.01,{ }^{*} \mathrm{p}<.05$.

To sum, the two models explained $51 \%$ of the variance in reading comprehension scores for medical students, $44 \%$ for science students, and $53 \%$ for arts students. It means that students' reading comprehension is influenced more by VLT for medical students and by VLT and DVK for science and arts students.

\section{Discussion}

The present study examined Saudi undergraduates' vocabulary breadth and depth and their relationships to reading comprehension. It also investigated the correlations between vocabulary aspects and reading comprehension and the mediating roles of gender and academic field in these relationships. The study addressed four research questions to achieve these objectives. The first research question sought to determine the performance of Saudi undergraduates on VLT, DVK, and reading comprehension. The study provided empirical evidence for the vocabulary breadth of Saudi EFL learners. The findings showed that students' vocabulary breadth decreased as the frequency level decreased. Students' scores on 1000, 2000, 3000 word levels were $72.5 \%, 51.4 \%, 41.6 \%$, respectively, which were far below the cutting point (29/30; i.e., 97\%) proposed by Webb et al. [76]. Therefore, students had problems in vocabulary breadth at the university level since knowing between 2000 and 3000 words families accounted for $95 \%$ of text comprehension [75]. Besides, the 4000 and 5000 word levels scored $38.7 \%$ and $35.4 \%$, respectively, which were also extremely below the cutting point $(24 / 39$; i.e., $80 \%$ ). This result provided between $86 \%$ and $89 \%$ of the lexical coverage of the texts, which did not guarantee to guess the meaning of the unfamiliar words in a text [37], [66]. The average vocabulary size of the current study was nearly 2700 word families, which went in line with previous studies (e.g., [5], [9], [12]). Generally, students could not reach $95 \%$, which represented the sufficient vocabulary size that enabled learners to read authentic texts [71].

On the other hand, students scored 72.43 (45.3\%) for vocabulary depth slightly lower than vocabulary breadth. Furthermore, students' knowledge of meaning scores
$(52.6 \%)$ was higher than their collocation knowledge (38.7\%). This result was confirmed by Schmitt [70], who reported that as vocabulary size increased, vocabulary depth lagged behind. Although the result indicated that students' receptive knowledge was slightly better than their productive knowledge, students seemed to have disappointingly low English competence. It was suggested that developing vocabulary depth was challenging in L2 learners due to their lack of exposure to the second language [41]. The findings of this study were similar to those of Mehrpour et al. [46], which reported a score of 82.46 (51.5\%), and Akbarian [2], which recorded 51.30 $(32.06 \%)$ on DVK. Conversely, these findings were inconsistent with some previous studies that recorded higher vocabulary depth scores (e.g., [1], [10], [62]). These studies reported that vocabulary depth was $97.3(60.85 \%)$ [1], 113.5 (71\%) ([62]) and $129.43(80.9 \%)$ [10]. This disagreement might be because the participants of these studies were intermediate and advanced learners, while the participants of this study included beginner learners.

Similarly, the participants' scores on reading comprehension were only $15.71(52.4 \%)$. This result was further down the criteria of the minimum comprehension score $(65 \%-70 \%)$ for the threshold of 3000 word families ([38]). It indicated that students were not able to comprehend a text well. It might refer to the deficiency of vocabulary breadth and depth since vocabulary was seen as a facilitator of reading comprehension. It was evident that students' lack of adequate vocabulary size and depth was a significant factor of difficulties in comprehending English texts. The findings were in accordance with several studies that confirmed Saudi EFL students' low reading proficiency (e.g., [6], [8], [55]). These studies asserted the crucial role that vocabulary knowledge played in promoting reading proficiency.

The findings showed that males outperformed females in vocabulary breadth, depth, and reading comprehension. The differences might be since most female students were taught by male instructors since female students studied on a separate campus. So, the lack of interaction might decrease students' participation and engagement in the learning processes. The finding went in line with the 
findings of several studies that showed males' superiority over females ([3], [11], [7], [9], [27], [78]). The findings contradicted several studies that showed females were significantly better than male students ([15], [20], [26], [30], [58], [68]), or showed no gender differences were observed ([16], [19], [35], [39], [45], [46], [59], [77]). These differences could be interpreted due to the context, age, classroom learning and differences in maturational development [31], [40].

Meanwhile, findings indicated significant differences due to academic field in vocabulary breadth between medical students and art students in favor of medical students. Besides, medical students' reading comprehension was significantly higher than their counterparts in science and arts, while the performance of medical students in vocabulary depth was higher but not statistically significant. The findings might be attributed to differences in the language of instruction. The language of instruction for medical students is English, whereas science and arts courses are delivered in the L1 language except for a few English courses. This variance gave medical students an advantage of acquiring more vocabulary breadth and depth and consequently improved their reading comprehension. The previous studies (e.g.,[26], [30], [36], [81]) had conflicting results, and their results could not be compared to the findings of this study since medicine major was not included in those studies, and this study is considered the first one to investigate this major.

Regarding the relationship of reading comprehension to the components of vocabulary knowledge, the findings revealed that VLT, DVK, DVKM, and DVKC were significantly correlated with $\mathrm{L} 2$ reading comprehension. The highest relationship was found between VLT and reading comprehension. The correlation between VLT and reading comprehension was fairly strong $(\mathrm{r}=.67)$ and close to the findings of the previous studies (e.g., [13], [14], [23], [46], [56], [61], [62], [64]). On the other hand, several studies indicated dissimilar findings with a robust correlation (e.g., [10], [50], [79]) or a moderate correlation (e.g., [4], [17], [72]) between VLT and reading comprehension. These differences might be attributed to the using different forms of VLT or being limited to only some frequency levels. This finding suggested that students' vocabulary size played a significant role in reading performance.

In addition, there was a moderately significant correlation $(\mathrm{r}=.57)$ between $\mathrm{DVK}$ and reading comprehension. This finding was in line with the findings found by many researchers (e.g., [72], 17). Nonetheless, a substantial number of studies reported a strong correlation (e.g., [1], [10], [23], [46], [50], [56], [62]), or a very strong correlation between DVK and reading comprehension [61], [64]. The dissimilarity between these findings might refer to the various forms, standardization, and length of the reading comprehension test administered in these studies, such as TOEFL, TOEFL-VIM, SLEP, Nationwide Unified Academic Ability Evaluation, and Longman TOEFL. Further, the samples recruited might affect the magnitude of the relationship between DVK and reading comprehension. Likewise, word association and collocation were positively correlated with reading comprehension, $\mathrm{r}=.55$ and $\mathrm{r}=.53$, respectively. This result was not surprising since both meaning and collocation signify the components of DVK. Furthermore, this finding was in agreement with the finding of Ma and Lin [43] and Qian [62]. Although the magnitudes of the correlation of word association and collocations reported in this study were slightly higher than Ma and Lin's ([43]) study and lower than Qian's [62] study, these correlations suggested the impact of word association and collocation on reading comprehension.

Additionally, comparing the magnitude of VLT and VDK indicated that VLT was a stronger predictor of reading comprehension than DVK. This result was consistent with the findings of several studies (e.g., [10], [17], [23], [50], [56]). Conversely, several studies revealed that DVK was more effective than VLT in predicting reading performance (e.g., [46], [61], [62], [64], [79], [72]). As VLT and DVK were positively correlated with reading comprehension, it was suggested that VLT and DVK were similarly powerful in predicting reading performance [62] regardless of which value was greater.

Moreover, VLT and DVK were found to be strongly correlated. This finding could be attributed to the interconnection between breadth and depth of vocabulary knowledge since they depend on each other. Thus, the two constructs play a vital role in reading comprehension and are considered two dimensions of the same entity [41]. The finding suggested that vocabulary breadth contributed to vocabulary depth; students with a large number of words had deep vocabulary knowledge. This study had evidence that VLT had a stronger effect than DVK on reading comprehension. This finding aligned with the previous research findings, which asserted a positive relationship between VLT and DVK (e.g., [10], [23], [46], [61], [62], [64], [72]).

The results of the hierarchical multiple regression showed that VLT was able to predict the variance in reading comprehension for male and female students, $\mathrm{R}^{2}=.39$ and $\mathrm{R}^{2}=.46$, respectively. This finding suggested that VLT affected reading comprehension with different magnitudes but significantly for both male and female students. When DVK was entered, it affected females' reading comprehension, in contrast to males, whose reading comprehension was not affected despite the equal two values of the explained variance. The models significantly explained $51 \%$ of the variance in reading comprehension for females and only $45 \%$ for males, which indicated that vocabulary knowledge played a more significant role for females. These findings suggested that gender had a mediating role in the interrelationships of 
VLT and DVK to reading comprehension. These findings could be interpreted in three ways. First, females tend to differ in their achievement orientations compared to males [39]. Second, females might benefit from the learning tasks due to their maturational development, especially in language learning [31]. Third, females use more strategies and a wide range of learning strategies than male students [42].

The findings revealed that academic field played a significant role in the interrelations between vocabulary knowledge and reading comprehension. For medical students, VLT predicted reading comprehension than science and arts students. This finding could be attributed to the extensive vocabulary among medical students and the adoption of English as the language of instruction in medical faculties. When DVK was inputted, it significantly affected the reading comprehension of science and arts students, in contrast to medical students, whose reading comprehension was not considerably affected. The findings suggested that students' reading comprehension was more influenced by VLT for medicine discipline and VLT and DVK for science and arts disciplines. Thus, academic field had a mediating role in the interrelationships of VLT and DVK to reading comprehension. These results could be attributed to the different vocabulary learning strategies, and the types of academic vocabulary adopted across disciplines. Tang and Tian [74] supported this explanation stating that art students had a wide range of learning strategies such as compensation, memory, affective and metacognitive strategies.

Interestingly, this is the first study examining the mediating effect of gender and academic field on the relationship between vocabulary knowledge and reading comprehension. Thus, this study provided a preliminary image of the effect of these variables, in combination with vocabulary knowledge, on reading comprehension.

\section{Conclusions}

This study addressed the correlations between the aspects of vocabulary knowledge (i.e., breadth and depth) and reading comprehension. It also examined the mediating role of gender and academic field in the relationship of VLT and DVK to reading comprehension. The descriptive analyses showed that Saudi students had between 2000 and 3000 word families at the college level, low vocabulary depth $(45.3 \%)$, and poor reading comprehension (52.4\%). In addition, male students outperformed female students in vocabulary size, depth, and reading comprehension. Meanwhile, medical students had superiority over science and arts students in VLT and reading comprehension. Vocabulary breadth and depth were significantly correlated with reading comprehension. The contribution of VLT and DVK to reading comprehension differs depending on gender and academic field. Notably, the study provided empirical evidence of the mediating role of gender and academic field on the relationship of VLT and DVK to reading comprehension.

\section{Pedagogical Implications}

This study has several pedagogical implications regarding the development of vocabulary knowledge to improve reading comprehension. First, the student's poor performance in VLT, DVK, and reading comprehension requires teachers to expose students to authentic reading materials to enrich their vocabulary capacity. These materials should combine vocabulary size with depth development such as synonymy, polysemy, and antonymy. Teachers have to focus on vocabulary from and use, including collocation, pragmatic, morphological, and pragmatic properties [29]. Besides, learning strategies are effective in language learning, so teachers should employ various learning strategies to help learners acquire vocabulary knowledge and reading comprehension. Moreover, language textbooks should be provided with adequate activities to promote students' vocabulary depth and breadth together since depth and breadth are essentially connected.

Second, due to the significant differences between male and female students in vocabulary breadth, depth, and reading comprehension, more attention should be paid to the teaching of female students. Teachers of female students should differentiate vocabulary and reading instruction to cope with female characteristics. In addition, male students' use of reading and vocabulary strategies differs from their female counterparts [51], [80]. Thus, teachers should pay attention to the learning strategies employed by female students and maximize the use of these strategies when teaching vocabulary and reading comprehension.

Third, since vocabulary breadth and depth contribute essentially to reading comprehension, curriculum developers should pay equal attention to vocabulary size and depth when designing language textbooks. Teachers also have to balance vocabulary breadth and depth to help students benefit from their vocabulary knowledge to enhance reading comprehension. Furthermore, as vocabulary breadth and depth are equally correlated with reading comprehension, teachers should give equal weight to the components when assessing vocabulary knowledge and reading comprehension [62].

Finally, the moderating role of gender and academic field on the relationship of vocabulary knowledge to reading comprehension may help teachers foster practical teaching approaches appropriate for male and female students. Teachers can also benefit from students' learning strategies across disciplines and generalize the effective teaching strategies for vocabulary and reading instruction. 


\section{Limitations}

This study has some limitations, which will be provided for further research in the future. Firstly, the instrument for vocabulary breadth used in this study has only five frequency levels; 1000 to 5000 , which was developed by Webb et al. [76]. Although these frequency levels provide useful findings, more frequency levels are recommended to generalize the study findings. Besides, examining the correlation of each frequency level with reading comprehension is recommended to identify the highly predictive frequency level. Another limitation is assessing vocabulary depth as a whole in this study; future studies may adopt multiple measures of vocabulary depth to gain insightful findings. Moreover, this study addressed the mediating roles of gender and academic field. Further studies should examine the mediating roles of other variables which may affect the interrelations between vocabulary knowledge and reading comprehension, such as self-efficacy, motivation, learning strategies, or memory. Finally, this study did not consider the students' various proficiency levels. Thus, conducting more studies with different language proficiency levels is warranted.

\section{REFERENCES}

[1] Abedi, D. (2017). The relationship between depth of vocabulary knowledge and reading comprehension of Iranian EFL learners. Journal of Applied Linguistics and Language Research, 4(4), 224-229.

[2] Akbarian, I. (2010). The relationship between vocabulary size and depth for ESP/EAP learners. System, 38(3), $391-401$

[3] AlAsmari, A., \& Ismail, N. (2012). Self-regulated learning strategies as predictors of reading comprehension among students of English as a foreign language. International Journal of Asian Social Science, 2(2), 178-201.

[4] Al-Khasawneh, F. (2019). The impact of vocabulary knowledge on the reading comprehension of Saudi EFL learners. Journal of Language and Education, 5(3), 24-34.

[5] Al-Masrai, A., \& Milton, J. (2012). The vocabulary knowledge of university students in Saudi Arabia. TESOL Arabia Perspectives, 19(3), 13-19.

[6] AlNooh, A. (2013). The effectiveness of reading techniques used in a Saudi Arabian secondary school classroom as perceived by students and teachers: A study of methods used in teaching English and their effectiveness. Arab World English Journal, 4(3), 331-345.

[7] Alonso, A. (2013). Receptive vocabulary size of secondary Spanish EFL learners. Revista de Lingüística y Lenguas Aplicadas, 8(1), 66-75.

[8] Al-Qahtani, A. (2020). Investigating metacognitive think-aloud strategy in improving Saudi EFL learners' reading comprehension and attitudes. English Language Teaching, 13(9), 50-62.
[9] Alqarni, I. (2019). Receptive vocabulary size of male and female Saudi English major graduates. International Journal of English Linguistics, 9(1), 111-119.

[10] AlQunayeer, H. (2021). An investigation of the relationship between reading comprehension, vocabulary knowledge, and English language proficiency level of Saudi EFL learners. Advances in Language and Literacy Studies, 12(2), 59-69.

[11] Al-Shumaimeri, Y. (2005). Gender differences in reading comprehension performance in relation to content familiarity of gender-neutral texts. Paper presented at the Second International Conference: Language, Culture and Literature., Minia University, Egypt.

[12] Altalhab, S. (2019). The vocabulary knowledge of Saudi EFL tertiary students. English Language Teaching, 12(5), $55-65$.

[13] AlTameemy, F., Daradkeh, A., \& Alhamod, A. (2018). The Relationship between EFL Students' Word-Knowledge in a Text and Their Reading Comprehension as Demonstrated by Saudi University Students. Journal of Education and Learning, 7(4), 236-246.

[14] Anjomshoa, L., \& Zamanian, M. (2014). The effect of vocabulary knowledge on reading comprehension of Iranian EFL learners in Kerman Azad University. International Journal on Studies in English Language and Literature, 2(5), 90-95.

[15] Anjum, S. (2015). Gender difference in mathematics achievement and its relation with reading comprehension of children at upper primary stage. Journal of Education and Practice, 6(16), 71-75.

[16] Asgarabadi, Y. H., Rouhi, A., \& Jafarigohar, M. (2015). Learners' gender, reading comprehension, and reading strategies in descriptive and narrative macro-genres. Theory and Practice in Language Studies, 5(12), 2557- 2564.

[17] Atai, M., \& Nikuinezhad, F. (2012). Vocabulary breadth, depth, and syntactic knowledge: Which one is a stronger predictor of foreign language reading performance?, Iranian Journal of Applied Linguistics, 15(41), 1-18.

[18] Cain, K. (2010). Reading development and difficulties. Blackwell Publishing.

[19] Catalan, R. (2010). Gender perspectives on vocabulary in foreign and second languages. Palgrave Macmillan.

[20] Cekiso, M. (2016). Gender differences in the reading comprehension of grade three rural learners in South Africa. International Journal of Educational Sciences, 13(2), 247-254.

[21] Chalari, A. (2017). The sociology of the individual: Relating self and society. SAGE publications Ltd.

[22] Chigayeva, S. (2001). The effects of discipline-specific background knowledge on reading comprehension [Master thesis, Iowa State University]. Retrospective Theses and Dissertations. 213.

[23] Choi, H-Y. (2013). Effects of depth and breadth of vocabulary knowledge on English reading comprehension among Korean high school students. Language Research 49(2), 419-452. 
[24] Dabbagh, A. (2016). The predictive role of vocabulary knowledge in listening comprehension: Depth or breadth? International Journal of English Language \& Translation Studies, 4(3), 01-13.

[25] Deimante, D. (2018). Challenges in prompting the development of reading skills. In D. Laiveniece (Ed.), Problems of and perspectives on language acquisition (pp. 14-22). Cambridge Scholars Publishing.

[26] Fan, N. (2015). A study of vocabulary knowledge and vocabulary learning strategies of Chinese EFL learners [Unpublished Doctoral Dissertation]. Macquarie University.

[27] Fardad, Z., Koosha, M., \& Shafiee, S. (2015). Relationship between EFL learners' multiple intelligence scores, gender, and their vocabulary knowledge. Research Journal of Recent Sciences, 4(12), 29-36.

[28] Grabe, W. (2009). Reading in a second language: Moving from theory to practice. Cambridge University Press.

[29] Gu, T. (2017). The effect of vocabulary knowledge on Chinese English learners' reading comprehension. International Journal of English Linguistics, 7(4), 45-55.

[30] Gu, Y. (2002). Gender, academic major, and vocabulary learning strategies of Chinese EFL learners. RELC Journal, 33(1), 35-54.

[31] Halpern, D. F. (2004). Sex differences in intelligence: Implications for education. In G. Boyle \& D. Saklofske (Eds.), The psychology of individual differences (pp. 291312). Sage.

[32] Kasim, U., Muslem, A., \& Mustafa, F. (2019). Differences in English proficiency test scores between students of social and natural sciences. International Journal of Instruction, 12(1), 479-492.

[33] Kasim, U., \& Raisha, S. (2017). EFL students' reading comprehension problems: Linguistic and non-linguistic complexities. English Education Journal, 8(3), 308-321.

[34] Khodadady, E., \& Dastgahian, B. S. (2012). Gender and field of study and performance on an English Language Proficiency Test. Theory \& Practice in Language Studies, 2(11), 2322-2329.

[35] Koc, D. K. (2016). The role of gender in reading comprehension: An analysis of college-level EFL students' comprehension of different genres. International Online Journal of Education and Teaching, 3(3), 218-227.

[36] Kruekaew, T., Tongkumchum, P., \& Choonpradub, C. (2008). Factors affecting English vocabulary skill of undergraduates at Prince of Songkla University, Pattani Campus. Asian Social Science, 9(4), 12-17.

[37] Laufer, B. (1992). How much lexis is necessary for reading comprehension? In P. Arnaud \& H. Bejoint (Eds.), Vocabulary and applied linguistics (pp. 126-132). Macmillan.

[38] Laufer, B., \& Sim, D. (1985). Measuring and explaining the reading threshold needed for English for academic purposes texts. Foreign language annals, 18(5), 405-411.

[39] Lee, S. (2020). Examining the roles of aptitude, motivation, strategy use, language processing experience, and gender in the development of the breadth and depth of EFL learners' vocabulary knowledge. SAGE Open, 10(4), 1-15.

[40] Lee, S., \& Pulido, D. (2017). The impact of topic interest, L2 proficiency, and gender on EFL incidental vocabulary acquisition through reading. Language Teaching Research, $21,118-135$.

[41] Li, M., \& Kirby, J. (2014). The effects of vocabulary breadth and depth on English reading. Applied Linguistics, $36(5), 1-25$

[42] Llach, M., \& Gallego, M. (2012). Vocabulary knowledge development and gender differences in a second language. Elia, 12(1), 45-75.

[43] Ma, Y., \& Lin, W. (2015). A study on the relationship between reading comprehension and English vocabulary knowledge. Education Research International, Article ID209154, 1-14.

[44] Masrai, A. (2019). Vocabulary and reading comprehension revisited: Evidence for high, mid-, and low-frequency vocabulary knowledge. SAGE Open, 9(2), 1-13.

[45] McGeown, S., Goodwin, H., Henderson, N., \& Wright, P. (2012). Gender differences in reading motivation: Does sex or gender identity provide a better account?. Journal of Research in Reading, 35(3), 328-336.

[46] Mehrpour, S., Razmjoo, S., \& Kian, P. (2011). The relationship between depth and breadth of vocabulary knowledge and reading comprehension among Iranian EFL learners. Journal of English Language Teaching and Learning, 222(53), 97-127.

[47] Michoriska-Stadnik, A. (2014). Gender-related distribution of direct learning strategies as a determining factor in successful second language acquisition. In W. Szubko-Sitarek, Ł. Salski, \& P. Stalmaszczyk (Eds.), Language learning, discourse and communication: Studies in honour of Jan Majer (pp. 117-132). Springer.

[48] Mohammed, Q., \& Rashid, R. (2017). Reading comprehension difficulties among EFL learners: The case of first and second year students at Yarmouk University in Jordan. Arab World English Journal, 8(2), 421-431.

[49] Mohammed, Q., \& Rashid, R. (2019). The sources of reading comprehension difficulties among Saudi EFL learners. Trends in Social Sciences, 1(1), 7-16.

[50] Moinzadeh, A., \& Moslehpour, R. (2012). Depth and breadth of vocabulary knowledge: Which really matters in reading comprehension of Iranian EFL learners? Journal of Language Teaching and Research, 3(5), 1015-1026.

[51] Montero-SaizAja, A. (2021). Gender-based Differences in EFL Learners' Language Learning Strategies and Productive Vocabulary. Theory and Practice of Second Language Acquisition, 2(7), 83-107.

[52] Nation, P. (1993). Vocabulary size, growth and use. In R. Schreuder \& B. Weltens (Eds.), The bilingual lexicon (pp. 115-134). John Benjamins.

[53] Nation, P. (2001). Learning vocabulary in another language. Cambridge University Press.

[54] Nation, P. \& Waring, R. (1997). Vocabulary size, text coverage and word lists. In N. Schmitt \& M. McCarthy 
(Eds.), Vocabulary: description, acquisition and pedagogy (pp. 6-19). Cambridge University Press.

[55] Nezami, S.. (2012). A critical study of comprehension strategies and general problems in reading skill faced by Arab EFL learners with special reference to Najran University in Saudi Arabia. International Journal of Social Sciences \& Education, 2(3), 306-316.

[56] Noro, T. (2002). The roles of depth and breadth of vocabulary knowledge in reading comprehension in EFL. Annual Review of English Language Education in Japan, $13,71-80$.

[57] Olmez, F., \& Saka, O. (2020). The role of vocabulary learning strategies in learning English and their use in the Turkish EFL context. In N. Alagozlu \& V. Kiymazarslan (Eds.), Current perspectives on vocabulary learning and teaching (pp. 120-151). Cambridge Scholars Publishing.

[58] Payne, T., \& Lynn, R. (2011). Sex differences in second language comprehension. Personality and Individual Differences, 50(3), 434-436.

[59] Phakiti, A. (2003). A closer look at gender and strategy use in L2 reading. Language Learning, 53(4), 649-702.

[60] Qian, D.D. (1998). Depth of vocabulary knowledge: Assessing its role in adults' reading comprehension in English as a second language [Unpublished doctoral dissertation]. University of Toronto, Toronto, Ontario, Canada.

[61] Qian, D. D. (1999). Assessing the roles of depth and breadth of vocabulary knowledge in reading comprehension. Canadian Modern Language Review, 56(2), 282-308.

[62] Qian, D. D. (2002). Investigating the relationship between vocabulary knowledge and academic reading performance: An assessment perspective. Language Learning 52(3), 513536.

[63] Qing, M. (2009). Second language vocabulary acquisition. International Academic Publishers.

[64] Rashidi, N., \& Khosravi, N. (2010). Assessing the role of depth and breadth of vocabulary knowledge in reading comprehension of Iranian EFL learners. Pan-Pacific Association of Applied Linguistics, 14(1), 81-108.

[65] Read, J. (1993). The development of a new measure of L2 vocabulary knowledge. Language Testing, 10, (3) 355-371.

[66] Read, J. (2000). Assessing vocabulary. Cambridge University Press.

[67] Riadil, I. (2020). Investigating EFL learners' reading comprehension problems and strategies in Tidar University. Journal of English Language and Language Teaching, 4(1), $48-58$.

[68] Salehi, M., Lari, Z., \& Rezanejad, A. (2014). The effects of gender and genre on language learners' reading comprehension ability. Education Journal, 3(5), 266-271.

[69] Schmitt, N. (2008). Instructed second language vocabulary learning. Language Teaching Research, 12(3), 329-363.

[70] Schmitt, N. (2014). Size and depth of vocabulary knowledge: What the research shows. Language learning, 64(4), 913-951.

[71] Schmitt, N., Jiang, X., \& Grabe, W. (2011). The percentage of words known in a text and reading comprehension. The Modern Language Journal, 95, 26-43.

[72] Sen, Y., \& Kuleli, M. (2015). The effect of vocabulary size and vocabulary depth on reading in EFL context. ProcediaSocial and Behavioral Sciences, 199, 555-562.

[73] Stæhr, L. (2008). Vocabulary size and the skills of listening, reading and writing. Language Learning Journal, 36(2), 139-152.

[74] Tang, M., \& Tian, J. (2015). Associations between Chinese EFL graduate students' beliefs and language learning strategies. International Journal of Bilingual Education and Bilingualism, 18(2), 131-152.

[75] Van Zeeland, H., \& Schmitt, N. (2013). Lexical coverage in L1 and L2 listening comprehension: The same or different from reading comprehension?. Applied Linguistics, 34(4), 457-479.

[76] Webb, S., Sasao, Y., \& Ballance, O. (2017). The updated Vocabulary Levels Test: Developing and validating two new forms of the VLT. ITL-International Journal of Applied Linguistics, 168(1), 33-69.

[77] Yang, T. (2020). A study on the relationship of middle school students' vocabulary breadth knowledge and listening comprehension. Educational Research and Reviews, 2(3). 7-13.

[78] Yazdanpanah, K. (2007). The effect of background knowledge and reading comprehension test items on male and female performance. The Reading Matrix, 7(2), 64-80.

[79] Zano, K., \& Phatudi, N. (2019). Relationship between vocabulary knowledge and reading comprehension of South African EFAL high school learners. Per Linguam, 34(3), 16-28.

[80] Zare, P. (2012). Language learning strategies among EFL/ESL learners: A review of literature. International Journal of Humanities and Social Science, 2(5), 162-169.

[81] Zhang, X., \& Ardasheva, Y. (2019). Sources of college EFL learners' self-efficacy in the English public speaking domain. English for Specific Purposes, 53, 47-59.

[82] Zhang, S., Zhang, X. (2020). The relationship between vocabulary knowledge and L2 reading/listening comprehension: A meta-analysis. Language Teaching Research.1-30. 